\title{
A esfera do trabalho como lócus de justiça social
}

\author{
Alex Pizzio \\ Programa de Pós-Graduação em Desenvolvimento Regional da Universidade Federal do Tocantins (UFT)
}

Recebido: 13/12/2012 Versão revisada (entregue): 18/03/2013 Aprovado: 22/03/2013

\begin{abstract}
Resumo
Este artigo se insere no rol dos trabalhos que visam contribuir com o debate sobre a justiça social tendo como referência o mundo do trabalho. Do ponto de vista teórico o estudo retoma as teorias sobre os bens no intuito de refletir acerca do papel desempenhado pelos bens na vida cotidiana, a distribuição do trabalho no espaço público e suas conseqüências. Neste sentido, na primeira parte do artigo se desenvolve o argumento geral, segundo o qual, o trabalho constituise em um bem. Na segunda parte, a abordagem refere-se aos aspectos relativos à estruturação e à distribuição do trabalho no espaço público e suas conseqüências. A adoção desses procedimentos analíticos possibilita um maior entendimento acerca da singularidade e dos modos como se produzem e reproduzem diversas formas de desigualdades sociais. As conclusões apontam para o fato de que trabalho constitui-se em importante bem de acesso, o produz um modelo originário de racionalidade e constitui-se em importante fonte moral.
\end{abstract}

Palavras-chave | Trabalho; bens; hierarquia; serviços de marcação; desigualdade social.

Código JEL | J20; J58; N30.

\section{THE SPHERE OF WORK AS A LOCUS OF SOCIAL JUSTICE}

\begin{abstract}
This article is part of the list of studies that aim to contribute to the debate on social justice with reference to the world of work. From the theoretical point of view the study incorporates the theories of goods in order to reflect on their role in everyday life, the distribution of work in the public space and its consequences. In this sense, the first part of the paper develops the general argument, according to which the work is considered to be goods. In the second part, the approach refers to those aspects of the structuring and distribution of work in the public space and its consequences. The adoption of these analytical procedures enables a greater understanding of the uniqueness and the ways they produce and reproduce various forms of social inequality. The conclusions point to the fact that work is a very important access goods, produces an originating model of rationality and constitutes an important source of moral.
\end{abstract}

Keywords | Work; property; hierarchy; markup services; social inequality.

JEL-Code | J20; J58; N30. 


\title{
LA ESFERA DEL TRABAJO COMO LOCUS DE JUSTICIA SOCIAL
}

\section{Resumen}

Este artículo se incluye entre aquellos que buscan contribuir con el debate sobre la justicia social teniendo como referencia el mundo del trabajo. Desde el punto de vista teórico el estudio retoma las teorías sobre los bienes, con la intención de reflexionar sobre el papel que desempeñan los bienes en la vida cotidiana, la distribución del trabajo en el espacio público y sus consecuencias. Para esto, en la primera parte del artículo se desarrolla el argumento general según el cual el trabajo constituye un bien. En la segunda parte, se abordan los aspectos relacionados a la estructuración y la distribución del trabajo en el espacio público y sus consecuencias. La adopción de estos procedimientos analíticos permite una mayor comprensión de las singularidades y los modos como se producen y reproducen diversas formas de desigualdades sociales. Las conclusiones señalan el hecho de que el trabajo se constituye en importante bien de acceso producido por un modelo originario de racionalidad y en importante fuente moral.

Palabras-clave | Trabajo; bienes; jerarquía; servicios de marcación; desigualdad social.

Código JEL | J20; J58; N30.

\begin{abstract}
A ordem econômica fundada na valorização do trabalho humano e na livre iniciativa tem por fim assegurar a todos existência digna, conforme os ditames da justiça social [...] A ordem social tem como base o primado do trabalho, e como objetivo o bem-estar e a justiça sociais (Artigos 170 e 193 da Constituição da República Federativa do Brasil, 1988).
\end{abstract}

\section{Introdução}

Considerando os avanços observados nas últimas décadas na sociedade brasileira, constata-se que ela se encontra em um momento de mudanças e de conformação a novas situações na estrutura social. Pode-se definir o momento como complexo, caracterizado por novas clivagens que transpassam as tradicionais estruturas de classe, desfazendo e criando novas identidades e revelando uma dinâmica societária, que, nos dizeres de Telles (2006, p. 143-144), é composta de formas distintas de sociabilidade que se conformam as intensas transformações da vida urbana, da organização da produção e do consumo, da organização da produção e do consumo. Fala-se aqui de novas hierarquias sociais, que se encontram atravessadas por enormes disparidades de renda, de cultura, de valores, mas, também, de acesso a mecanismos de representação e participação política; de diferenças no uso da cidade, nos modos de fixação e mobilidade no espaço urbano e acesso a bens materiais e simbólicos de uma sociedade de consumo pujante, mas também extremamente estratificada e excludente; de diferentes e muito desiguais formas de integração em um mercado que se altera em ritmo acelerado, 
desestabilizando posições consolidadas, desfazendo hierarquias ocupacionais tradicionais e criando novas clivagens e novas formas de diferenciação social.

Neste contexto, compreender o papel que os bens possuem e as funções que eles desempenham dentro da dinâmica social constitui-se em um importante veio analítico para compreendermos a complexidade da produção e reprodução das desigualdades sociais. Antes de adentrar propriamente o debate, vale esclarecer, brevemente, o que vem a ser um bem, uma vez que a sua definição varia de acordo com a esfera de análise. Afinal, o que é um bem? Segundo o Houaiss (2009), ele pode ser entendido como um conjunto de princípios fundamentais propícios ao desenvolvimento e ao aperfeiçoamento moral, seja dos indivíduos, seja da comunidade. Pode significar aquilo cuja posse e fruição (física ou espiritual) a coletividade julga ser conveniente para manutenção e/ou o progresso do homem. Do ponto de vista jurídico, o bem pode ser definido como coisa, corpórea ou incorpórea, da esfera econômica ou moral, suscetível de uma apropriação legal, isto é, tudo aquilo que é propriedade de alguém.

Mesmo sendo usuais, essas definições dizem muito pouco acerca dos processos que compõem a disputa por bens, do mesmo modo que revelam pouco acerca da sua utilização, sobretudo quando o cenário em questão envolve o debate por justiça social. Tendo essa dificuldade em mente, recorreu-se ao trabalho de uma antropóloga e de um economista, Mary Douglas e Baron Isherwood (2009), em que os autores, partindo do questionamento por que as pessoas querem bens, elaboram uma definição de bens que será extremamente proveitosa ao estudo proposto. Com base na análise desses autores, é possível adotar uma definição de bens segundo a qual eles são concebidos como objetos animados ou inanimados, materiais ou simbólicos, investidos de valores que são apropriados tanto para suprir necessidades, quanto para emitir sinais (mensagens) públicos.

\section{Os bens no mundo}

Em O mundo dos bens, Douglas e Isherwood (2009) oferecem uma excelente porta de entrada para o debate sobre as funções que os bens desempenham socialmente e sobre os motivos de as pessoas desejarem bens. Os autores questionam a ideia de pobreza como carência objetiva de posses, em favor de uma perspectiva que aborda a pobreza como medida de envolvimento social. Eles partem da ideia de que "as coisas cuja posse significa riqueza não são necessárias por elas mesmas, mas pelas relações sociais que elas sustentam.” (DOUGLAS, 2007, p. 19). Assim sendo, afirmam ser mais profícuo concentrar a atenção nos laços que os pobres conseguem estabelecer e manter com a sociedade, do que se fixar nas resultantes 
da carência material ${ }^{1}$. Desse modo, a pobreza encontra-se imbricada com as capacidades de que os sujeitos dispõem para obtenção e gerenciamento de informações. Pode-se dizer que se trata de um ponto nevrálgico, pois, "se suas conexões com a informação forem fracas, mais cedo ou mais tarde estará tão isolado que perderá o acesso a comida e ao calor." (DOUGLAS; ISHERWOOD, 2009, p. 35).

Esses elementos operam como pano de fundo para que os autores construam uma sofisticada teoria que vincula o grau de envolvimento social com a capacidade de consumo de bens, na qual os bens são algo mais do que meros objetos (abstratos ou não); eles são investidos de valores socialmente utilizados para exprimir categorias e princípios, dar sustentação a grupos, produzir mudanças ou criar permanências. Nessa perspectiva, os bens, além da supressão das necessidades, cumprem funções sociais.

Dentre as funções que os bens cumprem, duas são particularmente importantes para a discussão que ora se realiza. A primeira diz respeito ao fato de que os bens funcionam como marcadores mais ou menos temporários de categorias racionais. Desse modo, "comportar-se como agente econômico significa fazer escolhas racionais. Pode-se dizer que os bens reunidos em uma propriedade fazem afirmações físicas e visíveis sobre a hierarquia de valores de quem escolheu." (DOUGLAS; ISHERWOOD, 2009, p. 28).

Tal constatação é de extrema relevância. Com base nela, pode-se concluir que nada tem valor por si mesmo, os valores são, em essência, conferidos por juízos humanos. Assim, a importância de cada coisa depende do lugar que ocupa em uma série de outros objetos complementares. Em vez de tomar um objeto isoladamente para obter a informação que ele transmite, torna-se mais elucidativo buscar capturar todo o espaço de significação. Em outras palavras, deve-se investigar a realidade dentro do ambiente cultural que lhe é constitutivo.

O ambiente cultural, por suas características, pode ser entendido à semelhança de uma comunidade ${ }^{2}$. Os autores destacam que, na atualidade, as comunidades tendem a ser usadas como o lugar em que se descortina uma série de interações cujo caráter se expressa, em muitos casos, por meio dos laços de amizade e

\footnotetext{
${ }^{1}$ Embora seja pertinente a observação destacada pelos autores, não se deve perder de vista que tal questão não exclui o fato de as resultantes da carência material serem importantes. Essa questão será melhor desenvolvida adiante quando se aborda a ocupação do espaço público pelo trabalho informal.

${ }^{2}$ Mesmo tendo clareza de que o conceito de comunidade constitui-se em uma das noções mais vagas das ciências sociais, pode-se delimitar que, "no mínimo, comunidade geralmente indica um grupo de pessoas dentro de uma área geográfica limitada que interagem dentro de instituições comuns e que possuem um senso comum de interdependência e integração." (SHORE, 1996, p. 115).
} 
solidariedade. Ao mesmo tempo, a comunidade impõe limites aos seus integrantes, ela censura seus membros e pode até mesmo produzir exclusões, degradações e ostracismos $^{3}$.

Nessa abordagem, o caráter social da demanda é expresso por meio de serviços de marcação que os bens fornecem nos rituais de consumo, definido como um "sistema de rituais recíprocos que envolvem gastos para a marcação apropriada da ocasião, seja visitantes e anfitriões, seja da comunidade." (DOUGLAS; ISHERWOOD, 2009, p. 40). Em outras palavras, os autores chamam de rituais de consumo as marcas normais da amizade. Assim, o fluxo padronizado de bens de consumo permite identificar uma cartografia da integração social. Neste sentido,

a comunidade que envolve seus membros na maioria dos compromissos sociais tem mais rituais de consumo, e em tempos de crise a informação e o apoio fluem mais livremente. Membros de outro tipo de comunidade menos envolvidos em trocas rituais são mais vulneráveis a choques, econômicos ou não. Por implicação, esta explicação delega a responsabilidade aos outros consumidores pelo traçado de linhas de exclusão em torno de seus padrões de consumo (DOUGLAS; ISHERWOOD, 2009, p. 40).

Em decorrência, os sujeitos, como consumidores, estão continuamente fazendo seleções deliberadas entre seus pares, tanto para suas associações quanto para os rituais privados. Assim, a vida social passa a ser uma questão de alinhamentos favoráveis ou contrários, em que se elegem parceiros preferenciais de interação, constituem-se grupos, estabelecem-se ambientes de convivência e, para assinalar os alinhamentos, os bens funcionam como marcadores. Portanto, na vida social reside a importância dos usos que as pessoas fazem dos bens, já que eles operam como sinais. Neste sentido, os bens como objeto são neutros, todavia seus usos são sociais, e, portanto, podem ser usados para estabelecer aproximações ou para restringir movimentos. Em outras palavras, os bens "podem ser usados como cercas ou pontes.” (DOUGLAS; ISHERWOOD, 2009, p. 36).

\footnotetext{
${ }^{3}$ Em relação às coerções e exclusões que as comunidades realizam, os casos de xenofobia do Velho Mundo podem ser considerados emblemáticos. É sempre importante recordar que um dos pilares fundamentais da União Europeia foi a introdução das chamadas quatro liberdades, ou seja, a livre circulação de capitais, bens, serviços e pessoas. Na prática observa-se constantes ondas de protestos em relação à convivência com membros provenientes de outros locais, de outras etnias etc. Em parte, essas restrições devem ser entendidas no âmbito do mundo do trabalho e suas constantes transformações, que têm resultado na queda geral dos níveis e oferta dos postos de trabalho. No Brasil, a tendência é que esses tipos de conflitos adquiram uma aparência mais difusa. Essa questão será retomada adiante.
} 
Entretanto, o produto final, se pontes ou cercas, aproximações ou restrições, depende da maneira como as pessoas estão organizadas. Por conseguinte, os grupos, as comunidades, as associações e outros que integram o espaço público assemelham-se a uma caixa de sinais para os sujeitos e outros agrupamentos. Decorre então a necessidade de tentar descobrir o sistema de respostas que opera entre o modo como as pessoas vivem, quando enunciam coisas sobre elas mesmas, por meio dos bens, em um determinado ponto do tempo, e o que fazem sobre esse modo de viver, depois de receber as mensagens e começarem a emitir uma nova rodada de sinais. Na perspectiva dos autores,

precisamos prestar atenção quando o consumidor tem sucesso em abrir certas portas e fechar outras às tentativas menos bem-sucedidas de outros consumidores. Precisamos nos interessar pela infinidade de maneiras através das quais o consumidor usa bens para criar barreiras contra outros indesejados. Isto é cultura, essencialmente um conjunto de princípios justificadores para reunir apoio e solidariedade e um conjunto de sinais de entrada proibida (DOUGLAS; ISHERWOOD, 2009, p. 44).

Com base nessas considerações, pode-se falar do consumo como produtor de interações que conduzem a processos de reflexividade, eleição de parceiros e projetos. Esta ideia permite situar a crítica que alguns autores, como Rudá Ricci (2010), fazem às políticas sociais do governo Luís Inácio Lula da Silva, segundo a qual elas promovem a inclusão social de parcelas da população pelo consumo. Para o autor, o governo Lula adotou um modelo de gerenciamento em que o Estado aparece como ator fundamental e indutor do processo de desenvolvimento. Nessa perspectiva, o autor defende que os movimentos sociais devem ter por objetivo primeiro

a luta por direitos. A inscrição, aceitação e institucionalização de direitos universais que garanta a autonomia política e social. Em segundo lugar, a sustentabilidade ou garantia desta conquista, o que significa aumentar o poder da sociedade civil no interior do Estado. Sem participação e controle social, os direitos tornam-se uma dádiva e se reduzem a interesses de grupos sociais. Somente o controle social sobre o Estado articula e dá sentido universal aos direitos e configura um novo país. Infelizmente, no Brasil de hoje, o que temos é a criação do pacto fordista tupiniquim, que gera inclusão no mercado de consumo, mas não inclusão no processo decisório da política pública brasileira. Continuamos com uma cidadania inacabada. E efetivamos a modernização conservadora em nosso país (RICCI, 2010, p. 3). 
Ainda na perspectiva desse autor, na atualidade, vivencia-se um processo de instauração de "um modelo gerencial e de estrutura de poder político a partir do Estado. Está circunscrito ao conceito de modernização conservadora." (RICCI, 2010, p. 9). Este modelo é denominado pelo autor como lulismo e sua dinâmica tem a nova classe média como seu alvo e foco principal. Segundo ele,

Lula fala para a nova classe média, que até ontem foi pobre. Estamos falando de quase $50 \%$ da população brasileira (que recebe até 10 salários mínimos de renda mensal familiar). Ele mesmo tenta criar a imagem de representante desta classe, como ex-metalúrgico e retirante que chegou ao posto maior da gestão pública nacional e se tornou astro internacional. Por falar de uma classe em transição, acaba por atingir os menos abastados, além desta classe média baixa. O lulismo trata da esperança de sucesso familiar (RICCI, 2010, p. 9).

Em relação aos valores sociais que emergem dessa nova classe média com base no lulismo, o autor enfatiza:

São conservadores e individualistas. Religiosos, tratam da fé como instrumento de negociação para o sucesso pessoal e familiar. São refratários a mobilizações sociais, ao espaço público, não seguem líderes (daí não aceitar a tese de André Singer de que o lulismo é uma vertente do bonapartismo) e sente que está sendo incluída no país pelo consumo. Formam um caldo de cultura popular muito conservador, que não gosta de confronto, de rupturas, da agenda de direitos civis (RICCI, 2010, p. 9).

Contudo, mesmo considerando a pertinência dessas críticas, há que se reconhecer que projetos que pretendem ser alternativas de um modelo excludente começam pelo consumo. É o caso, por exemplo, dos primórdios do cooperativismo, em que os Pioneiros de Rochdale, ao criarem a primeira cooperativa, que congrega princípios aceitos até os dias atuais como balizadores da doutrina cooperativista, o fizeram estabelecendo uma cooperativa de consumo. Tratava-se de possibilitar o acesso, aos trabalhadores, a formas mais dignas de consumo.

Neste sentido, vale lembrar que os trabalhadores naquele contexto eram expropriados não somente nas relações de trabalho, mas, em igual medida, nas relações de consumo, que muitas vezes se apresentavam viciadas pela relação capital versus trabalho. Tendo apresentado esses elementos, e tendo como referência a discussão realizada até o momento, pode-se seguir para o segundo aspecto relevante para a discussão, qual seja: os bens funcionam como acessórios rituais. 
O bem, como objeto, é um acessório ritual, entretanto, ele é um acessório que opera no consumo, porque o consumo é um processo ritual cuja função primária é dar sentido ao fluxo incompleto dos acontecimentos. Mas o que é esse fluxo incompleto dos acontecimentos? Pode-se dizer que seus limites e seus significados são definidos em uma relação direta com a mercadoria, pois a mercadoria é o meio não verbal para a faculdade humana de criar. Não obstante, há uma ausência de significado na mercadoria como objeto. Para que ela possa circular e completar o fluxo dos acontecimentos, é necessário que o objeto seja dotado de valor, de significado, e esse significado só existe porque ele é um suporte ritual. A seguir, aborda-se esse processo de forma mais detalhada.

A questão dos significados envolve uma necessidade adicional: o imperativo social de fixação de significados públicos, pois eles são difíceis de serem captados, embora cotidianamente as pessoas se deparem com conjuntos de impressões. Enquanto um sujeito apresenta uma percepção cujo vetor de sentido aponta determinada direção, um outro apresenta um sentido diferente em relação ao mesmo acontecimento. Em decorrência, pode-se dizer que um dos principais problemas da vida social é fixar os significados de modo que fiquem estáveis por algum tempo. Pois,

sem modos convencionais de selecionar e fixar significados acordados falta uma base consensual mínima para a sociedade. Tanto para a sociedade tribal quanto para nós, os rituais servem para conter a flutuação dos significados. Os rituais são convenções que constituem definições públicas visíveis. Antes da iniciação havia um menino, depois um homem, antes do rito do casamento, havia duas pessoas livres, depois dele, duas reunidas em uma. Antes da internação no hospital, o atestado médico da doença; antes do atestado de óbito, o morto é considerado vivo [...] viver sem rituais é viver sem significados claros e, possivelmente, sem memórias. Alguns são rituais puramente verbais, vocalizados, não registrados; desaparecem no ar e dificilmente ajudam a restringir o âmbito da interpretação. Rituais mais eficazes usam coisas materiais, e podemos supor que, quanto mais custosa a pompa ritual, tanto mais forte a intenção de fixar significados. Os bens nessa perspectiva são acessórios rituais; o consumo é um processo ritual cuja função primária é dar sentido ao fluxo incompleto dos acontecimentos [...] Daqui é um passo curto para identificação do objetivo global que supõem-se - os seres racionais, por definição, consideram. Sua própria racionalidade deve pressioná-los a dar sentido ao seu ambiente (DOUGLAS; ISHERWOOD, 2009, p. 112).

Portanto, o objetivo mais geral do consumidor só pode ser o de construir um universo inteligível com os bens que escolhe. A construção cognitiva ocorre em um universo social, com a necessidade de demarcação da dimensão temporal. Neste sentido, a passagem do tempo passa a ser repleta de significados e os bens 
são utilizados para delimitar esses intervalos. Sua variação de qualidade surge com a necessidade de estabelecer uma diferenciação entre a passagem do tempo e o ciclo da vida (DOUGLAS; ISHERWOOD, 2009).

As percepções em relação aos acontecimentos cotidianos, igualmente, variam no espaço e, assim, vinculado "ao processo cultural, suas divisões são carregadas de significados: casa, tamanho, o lado da rua, a distância de outros centros, limites espaciais - todos são categorias conceituais" (DOUGLAS; ISHERWOOD, 2009, p. 114). Ainda, prosseguem os autores:

a escolha do bem cria continuamente certos padrões de discriminação, superando ou reforçando outros. Os bens são, portanto, a parte visível da cultura. São arranjados em perspectivas hierárquicas que podem dar espaço para a variedade total de discriminações de que a mente humana é capaz (DOUGLAS; ISHERWOOD, 2009, p. 114).

Em outras palavras, os bens são usados para tornar visível um conjunto particular de julgamentos nos processos fluidos de classificação de pessoas e eventos, e, neste sentido, as pessoas precisam de bens para compreender o que se passa à sua volta. A maneira de conceber os bens como substantivos à interação social também é compartilhada por outros autores. Para Walzer (2003, p. 6-8),

os bens com seus significados - por causa de seus significados - são o meio fundamental das relações sociais, entram nas mentes antes de passar pelas mãos; as distribuições se modelam segundo conceitos compartilhados do que são os bens e para que eles servem. [...] é o significado dos bens que define sua movimentação. Os critérios e os acordos distributivos não são intrínsecos ao bem em si, mas ao bem social. Se entendermos o que ele é, o que significa para aquele para quem é um bem, entenderemos como, por quem e por quais motivos deve ser distribuído.

Já é possível então responder ao questionamento de Douglas e Isherwood (2009): afinal para que as pessoas querem bens? Nas palavras dos autores:

trata-se sempre de controle. Nossa resposta requer que façamos uma suposição: supomos que há um conjunto compreensivo e fundamental de desejos humanos que diz respeito ao controle de outros humanos (e também a fugir do controle alheio). $\mathrm{O}$ foco no controle abre caminho para envolver culturas políticas no ciclo econômico. Teremos eventualmente um modelo que começa com os consumidores cujas tendências culturais comandam sua demanda por bens. A demanda do consumidor comanda a produção, e a produção provocada pela demanda comanda a tecnologia e a tecnologia tem efeitos nas vidas 
humanas. Por causa dos resultados da tecnologia os consumidores se agrupam, e o agrupamento pode ser em grandes e arrumadas pirâmides ou em grandes montanhas desarrumadas, ou em pequenos blocos altamente divisíveis, ou então as pessoas podem escapar e viver separadas em paisagens esparsas. Cada ambiente social permite apenas certos tipos de controle, e isso permite que a tendência cultural dominante se desenvolva (DOUGLAS; ISHERWOOD, 2010, p. 47).

Tendo delimitado essas questões pretende-se, nas próximas páginas, valer-se desse referencial teórico para pensar o trabalho como bem e como a sua distribuição no espaço público colabora para estabelecer hierarquias sociais.

\section{O trabalho como bem}

Diante do que foi exposto até o momento, destacam-se três características importantes acerca dos bens e que são úteis à proposta deste trabalho. São elas:

a) os bens realizam serviços de marcação;

b) são investidos de significados e, portanto, operam como sistemas de informação;

c) são acessórios rituais e, neste sentido, sua disposição em um universo cultural qualquer integra redes de suporte a adscrição de valores.

Antes de tratar dessas questões, deve-se destacar uma diferença básica existente entre os bens mercadorias que são objeto de consumo - como os apontados por Douglas e Isherwood (2009) - e o trabalho como bem social. Embora o trabalho apresente um conjunto de características similares aos bens de consumo, sua natureza é diferente. A dessemelhança entre os bens mercadoria e o trabalho como bem social encontra-se na gênese de ambos. O trabalho, declara Friedmann (1973, p. 19),

merece ser considerado como traço específico da espécie humana. O homem é um animal social que, ainda hoje, através de ritmo na marcha do progresso técnico, de evolução na estrutura e no nível econômico das sociedades se ocupa essencialmente de trabalho. O trabalho é um denominador comum e uma condição de toda a vida humana em sociedade.

Na mesma linha, Albornoz (2008, p. 58) ressalta que, em épocas passadas, 
o trabalho foi concebido por alguns como um estímulo para o desenvolvimento do homem e não como obstáculo. O trabalho é a expressão do homem e expressão do indivíduo. O homem se torna um criador por sua própria atividade; pode realizar qualquer coisa. $\mathrm{O}$ trabalho é a melhor maneira de preencher sua vida.

Com base nesses entendimentos, pode-se referir ao trabalho em dois sentidos. $\mathrm{O}$ primeiro diz respeito ao seu caráter ontológico ${ }^{4}$. O trabalho, além de fornecer sentido ao vivido (Antunes, 1999), também promove a inserção dos sujeitos em um universo de representação social, em que as experiências no trabalho se traduzem em construção identitária. Em outros termos, o trabalho percebido conforme uma lógica de contribuição social confere ao sujeito um sentido, e, ao fazê-lo, possibilita um retorno para o sujeito que trabalha em termos de realização pessoal. Nesta perspectiva, é possível falar do trabalho como um bem constitutivo.

Em outro sentido, pode-se afirmar que o trabalho é um bem de acesso. O trabalho como atividade produtiva, além de propiciar meios de subsistência, permite o acesso a outros bens, materiais ou simbólicos, por meio das possibilidades abertas ao consumo. Trata-se de um aspecto importante da questão, pois, como visto, o consumo possibilita que os sujeitos ampliem seu leque de interações sociais. Conforme Martins (1997), no âmbito do consumo, os sujeitos inserem-se na sociedade capitalista. Neste sentido, caso se interprete corretamente Douglas (2007), os processos de consumo devem considerar a interação entre formas de empregos e cultura. Desse modo, o esquadrinhar do consumo deve levar em conta os padrões culturais, entendendo que esses padrões dependem da forma de organização, e que eles ditam qualidades para bens de consumo. A cultura, segundo esse modelo, desenvolve-se em um ambiente no qual os tipos de atitudes morais, que uma organização requer para que possa funcionar, são vistos como emergindo em respostas a prêmios e a penalizações que a organização emprega. Cultura e organização produzem uma a outra.

\footnotetext{
${ }^{4}$ Esta é uma questão que vem de longa data e diversos autores se debruçaram sobre ela. $\mathrm{Na}$ sociologia clássica, Marx (2002) realiza uma análise detalhada do significado concreto do trabalho para o desenvolvimento capitalista. Ele destaca que a essência do homem está no trabalho e o que os homens produzem é o que eles são. Em outras palavras, o homem é o que ele faz. Neste sentido, o trabalho constitui-se em um elemento ontológico na formação do ser social.
} 


\section{Redes de suporte de discriminação de valores e sistemas de marcação social}

Como se verificou, os bens são acessórios rituais. Do ponto de vista dos objetos, eles são integrados em conjuntos dispostos de maneira a possibilitar a formação de uma rede de suporte adscrição de valores. Propõe-se então pensar a disposição dos objetos em um ambiente cultural qualquer, e, ao fazê-lo, refletir sobre a distribuição do trabalho no espaço público. Que consequências, ou, melhor dizendo, que relações sociais podem ser inferidas dessa disposição?

Em geral, essa disposição tem basicamente dois referenciais. O primeiro é aquele que se pode imaginar invadido pela dimensão do mercado, que traça linhas gerais acerca das mercadorias como necessidades de efetivação de um consumo que sustenta relações de produção e circulação de mercadorias e que, por fim, dispõe acerca da divisão social do trabalho.

Neste sentido, Costa (1999, p. 4) destaca que a

produção da mercadorias, como forma generalizada da produção humana, subordina a existência humana ao consumo mediatizado pelo mercado. Só depois de realizados como valor de troca, os objetos, frutos do trabalho humano, são disponibilizados para o consumo e para saciar as necessidades humanas. Primeiro compramos e depois comemos! Aí vem a primeira questão - como existir e sobreviver sem entrar na esfera do mercado? Na sociedade capitalista isso é impossível, já que o mercado é a grande instância que mediatiza as relações entre os homens.

Nessa mesma linha, Charles Taylor (1997) ressalta que o mercado é, com o Estado, uma instituição central no mundo moderno. Ele atua, dentre outros processos, na instituição de hierarquias valorativas por meio da articulação da subjetividade moderna. Dessa forma, o mercado, dentre suas funções, age como uma fonte moral para o self com repercussões na construção identitária dos sujeitos.

O segundo referencial é a seleção que os indivíduos efetuam em relação aos objetos, para oferecer suporte ao conjunto ritual, em uma série de rituais que dizem respeito às interações mais valorativas de uma cultura. Então, a grande questão é que a mercadoria, nesse contexto, não tem sentido, porque ela é imposta por uma estrutura de mercado, constituída para que as relações se formem.

Quando a questão se relaciona à dimensão de um processo ritual que dá sentido ao fluxo incompleto dos acontecimentos, esse fluxo é reconhecido no trabalho, ao passo que a mercadoria apresenta uma carga negativa já apontada por Marx (2002) e diz respeito ao trabalho morto. Pode-se dizer que, quando se reconhece um 
bem, de certa maneira, o suporte rirtual se faz presente, para que as interações e elaborações humanas sejam significativas no contexto de uma cultura.

De acordo com a lógica ritual, há pelo menos dois aspectos a serem enfatizados. O primeiro diz respeito ao ato de trabalhar, que em si mesmo constitui-se em um ato ritual. Neste sentido, os objetos que integram o ambiente de trabalho interagem conformando um aspecto da rede. Por outro lado, a disposição do trabalho no espaço público completa a rede, que será explorado com maior profundidade.

Abordou-se até o momento o argumento geral, segundo o qual o modo como os bens são dispostos em um ambiente qualquer configura uma rede de suporte adscrição de valores. Nessa perspectiva, e concebendo o trabalho como um bem social, a maneira como o trabalho aparece distribuído no espaço público, em suas mais variadas formas, configura uma rede de suporte que discrimina valores. Quando se tratam essas questões no campo empírico, percebe-se que os valores discriminados pela rede operam ora como elementos de integração entre grupos e sujeitos, ora como elementos que reforçam hierarquias e produzem estranhamentos a grupos e sujeitos. Esses eventos não são de difícil visualização ${ }^{5}$.

O pressuposto básico é que a distribuição do trabalho no espaço público conforma uma rede que discrimina valores e, com base nessa valoração, cria ambientes $^{6}$, estabelece lugares sociais mais ou menos valorizados. Desse modo, certas áreas do espaço urbano abrigam determinados conjuntos de atividades em detrimento de outras. Neste sentido, pode-se dizer que a base espacial que abriga atividades produtivas projeta sobre elas próprias, e sobre aqueles que delas se ocupam, uma expectativa valorativa que pode ser positiva ou negativa. Fala-se de lugares sociais, microambientes ${ }^{7}$ no espaço urbano, no qual algumas atividades e sujeitos são mais valorizados que outros.

Nessa perspectiva, a delimitação dos microambientes leva em conta a distinção elaborada por Milton Santos (2008) entre espaço como ente indiferenciado que se configura por estruturas sociais, e lugar como configurações de forma e funções

\footnotetext{
${ }^{5}$ Em outras áreas do conhecimento os estudos sobre a distribuição das atividades e ocupações no espaço urbano tem sido uma constante. Diversos deles vêm sendo produzidos pelo Observatório das metrópoles e podem ser acessados. Em geral, esses estudos levam para o centro do debate o papel das cidades no contexto de transformações em escala global. Uma excelente abordagem dessas questões é realizada por Bógus e Pasternack (2009).

${ }^{6}$ Ambiente, por definição, corresponde ao conjunto de condições materiais, culturais, psicológicas e morais que envolve uma ou mais pessoas (HOUAISS, 2009).

${ }^{7}$ Adota-se a expressão microambiente em vez de termos tais como zonas, bairros, áreas, por entender que o microambiente fornece um referencial mais preciso, uma vez que, uma zona, um bairro, uma área podem abrigar mais de um microambiente, o que não invalida as ocorrências em que um microambiente possa corresponder a totalidade de um bairro, de uma zona ou de uma área.
} 
organizadas socialmente por processos que fazem mediações com as estruturas sociais. Para o que interessa neste estudo, os microambientes são lugares estabelecidos em uma hierarquia social das disposições geográficas, que consideram formas recíprocas de movimentação de pessoas neles envolvidas, segundo tipos de atividades e finalidades de inserção social. Eles se estabelecem em conformidade com a capacidade de organização que os lugares apresentam para o desenvolvimento de determinada atividade.

Como ocorre essa operação? Não são poucos os casos em que uma atividade ou um sujeito pode obter um status maior pelo fato de desempenhar ou realizar suas atividades em um ambiente considerado nobre ${ }^{8}$. É de amplo domínio público que certos profissionais e certas atividades, tais como cirurgiões plásticos, advogados de grande renome e outros, tendem a estabelecer suas clínicas e escritórios em regiões mais valorizadas da cidade em detrimento de áreas periféricas ${ }^{9}$. Um médico (independentemente da especialidade) que exerça suas atividades profissionais em uma clínica situada na periferia da cidade assume um status inferior em comparação com outro que preste os mesmo serviços numa clínica estabelecida em uma região nobre da cidade. Neste sentido, projeta-se sobre a atividade e sobre o sujeito que a desempenha uma expectativa em relação à qualidade do trabalho, à qualificação do sujeito e suas possibilidades futuras. Esse exemplo pode-se estender a uma infinidade de atividades ${ }^{10}$.

Analogamente, o inverso também é verdadeiro. Uma atividade ou um profissional pode experimentar um status desvalorizado em virtude de sua inserção em áreas consideradas menos valorizadas ou periféricas. A presença de certas atividades em determinadas regiões da cidade pode servir de mote de desvalorização da região, bem como de outras atividades adjacentes, como nas áreas que abrigam galpões de

8 Essa questão desdobra-se e se complementa na constante valorização territorial que determinadas áreas recebem em razão da incidência de certas atividades.

${ }^{9}$ Não se desconhece que o estabelecimento de uma atividade, de uma empresa, de um profissional nas diversas regiões que compõem o ambiente urbano de uma cidade sofra influência de outros fatores, tais como capacidade de investimento, projeção de consumo, questões ambientais, etc. Contudo, tais questões não inviabilizam os argumentos que se vêm desenvolvendo.

${ }^{10}$ Um trabalhador empregado no Vale do Silício, pelo simples fato de integrar aquele ambiente, tem projetado sobre o seu trabalho uma expectativa valorativa positiva que lhe confere um status superior. Tal fato pode ser explicado em razão de o Vale do Silício ser reconhecido pela alta qualificação daqueles que trabalham nas empresas lá estabelecidas. No Brasil estudos têm sido realizados enfocando tais questões. Neste sentido, Mamão e Santos (2004) elaboraram, com base em dados coletados pelo Instituto Brasileiro de Geografia e Estatística (IBGE) um mapa referencial das cidades brasileiras consideradas polos de inovação, e a cidade de São Carlos, localizada a $250 \mathrm{~km}$ da capital paulista, ganhou fama não só por de abrigar um grande polo tecnológico, mas por ser conhecida por aglutinar um alto índice de profissionais com nível de doutorado. 
reciclagem, por exemplo. Tanto atividade, quanto sujeitos e local ficam subordinados a um status inferior e desvalorizado que marca profundamente quem as vivencia ${ }^{11}$.

Essas observações, entretanto, deixaram em aberto algumas questões. Alguém poderia contrapor-se a esses argumentos, apelando para a lógica de valorização espacial e citando a tendência logística de situar grandes empresas, complexos e outros, em áreas que, do ponto de vista financeiro, não são tão valorizadas. Um exemplo é a implantação da unidade produtiva da General Motors ${ }^{12}$, no município de Gravataí, no estado do Rio Grande do Sul.

A empresa instalou-se em uma região mais periférica, local de baixa valorização econômica. Convém enfatizar que, apesar do grande apelo logístico, o fato de o terreno situar-se às margens da autoestrada, facilitando o acesso e o escoamento da produção, não foi o aspecto determinante da escolha do local. Nesses casos, as determinantes e a valorização espacial vinculam-se à infraestrutura criada e disponibilizada para a implantação dessas unidades e às políticas de incentivos fiscais.

Contudo, a disposição das outras empresas que compõem o complexo segue a mesma lógica, com as mais valorizadas situadas mais ao centro, e as menores, mais à periferia. Do ponto de vista da repercussão para os trabalhadores, o fato de desempenhar suas atividades profissionais em tal complexo transfere a esses sujeitos certo status profissional, que é maior para aqueles que ocupam cargos da montadora e variável para aqueles que desempenham suas atividades em empresas fornecedoras que se situam no pátio da montadora ${ }^{13}$.

Nos exemplos citados, lida-se com hierarquias que se traduzem em estratificação e diferenciação de status, seja pela diferenciação obtida na comparação entre sujeitos que desempenham atividades diferentes, seja aquela entre sujeitos que realizam as mesmas funções. Essas questões encontram-se, igualmente, imbricadas com a ideia de qualificação e desqualificação (ou não qualificação) e seguem uma longa tradição que combina a meritocracia e a ideologia do mercado livre como medida de justiça.

Segundo Walzer (2003), o princípio fundamental da ideia de meritocracia é simplesmente que se deve reservar os melhores cargos e ocupações a pessoas com

\footnotetext{
${ }^{11}$ Para uma ampliação sobre o debate acerca do status desvalorizado da atividade de catação, ver Pizzio $(2007 ; 2009)$.

${ }^{12}$ Para efeitos de argumentação, não se considera a disputa entre diversos municípios do Rio Grande do Sul para sediarem a referida empresa e, igualmente, não considera a valorização que o município obteve com a implantação dessa montadora.

${ }^{13}$ Pôde-se colher tais depoimentos e impressões em eventos do qual se participou, quando atuava como consultor na prefeitura do município de São Leopoldo (RS) e em diversos eventos realizados pelo Sindicato dos Metalúrgicos daquela região.
} 
maior qualificação, pois a qualificação é um caso especial de mérito. Nesses casos, as pessoas podem merecer ou não suas qualidades, mas ocupam os lugares nos quais suas qualidades se enquadram. A essa visão combina-se uma outra, a que confere ao mercado o critério de justiça. Deste ponto de vista, o mercado, quando é livre, oferece a cada qual o que merece. Seguindo essa lógica, o mercado recompensa as pessoas na justa medida das suas contribuições para o bem-estar dos outros. Assim, os "bens e serviços que fornecemos são avaliados pelos consumidores em potencial desta ou daquela maneira, e esses valores são agregados pelo mercado, que define o preço que recebemos. E esse preço é o nosso mérito." (WALZER, 2003, p. 145). Deste modo, quanto maior for a qualificação do sujeito, maior será sua retribuição.

Mesmo reconhecendo que esse sistema avaliativo tem sido considerado válido em muitas sociedades, Walzer (2003, p. 195) tem questionado sua legitimidade. Segundo ele, "no sentido exato da palavra não existe meritocracia. Sempre se fizeram escolhas particulares entre possíveis 'méritos' ou, mais exatamente, no conjunto das qualidades humanas e, depois, entre indivíduos relativamente qualificados".

Esses apontamentos permitem dar um passo adiante. Douglas e Isherwood (2009) mostram que os bens integram redes de suporte adscrição de valores. Propõe-se, segundo tal concepção, que, em relação ao trabalho, essa rede forma-se com base na distribuição das atividades no espaço público. Pode-se falar de outra característica: os valores discriminados pela rede operam como sistemas de marcação social. Em outros termos, o trabalho, ao transferir expectativas valorativas às atividades e a seus participantes, influencia não somente as possibilidades futuras, mas impõe posições na estratificação social, do mesmo modo que exerce influência na hierarquia das ocupações.

Há, em cada atividade, em cada ocupação, um conjunto de signos/sinais, que são valorados e convertidos em marcas sociais vinculadas aos sujeitos que vivem de determinadas atividades, em determinados lugares. Quando se detém nas atividades de alto prestígio e nas ocupações dispostas em áreas nobres, pode-se observar que os sinais emitidos tendem a refletir, em sua maioria, representações positivas.

Quando se fala de atividades e sujeitos vistos como socialmente desvalorizados, o constructo valorativo que define sujeitos e situações apoia-se na percepção de certos signos externos de inferioridade que repercutem nas representações sociais acerca desses sujeitos, e tendem a reproduzir imagens distorcidas, verdadeiras caricaturas de quem desempenha uma atividade identificada como menos digna ou mesmo degradante. Essas questões podem ser interpretadas como o trabalho árduo, descrito por Walzer (2003). Para ele, o adjetivo árduo corresponde a algo brutal, desagradável, difícil de suportar.

O autor continua: 
Nesse caso, a palavra define trabalhos que parecem penas criminais, trabalhos que ninguém procura e não escolheria se tivesse ao menos uma alternativa muito pouco melhor. Esse tipo de trabalho é um bem negativo, e costuma carregar consigo outros bens negativos: pobreza, insegurança, enfermidades, riscos físicos, desonra e degradação. Não obstante é trabalho socialmente necessário; é preciso fazê-lo e isso significa que é preciso encontrar alguém para tal. A solução convencional desse problema tem a forma de uma equação simples: o bem negativo iguala-se ao status negativo das pessoas em cujas mãos é depositado. Distribui-se trabalho duro para pessoas degradadas. Os cidadãos têm liberdade; o trabalho é imposto a escravos, estrangeiros residentes, trabalhadores convidados - todos forasteiros. Alternativamente, os compatriotas que fazem esse trabalho são transformados em forasteiros locais, como os intocáveis da Índia, ou os negros norte-americanos após a escravatura. Em muitas sociedades, as mulheres têm sido o mais importante grupo de forasteiras locais, fazendo os serviços que os homens desdenham e liberando os homens, não só para as atividades econômicas compensadoras, mas também para a cidadania e a política. [...] a ideia em todos os casos é cruel: gente negativa para bens negativos. O serviço deve ser prestado por pessoas cujas qualidades se presume que seja compatível. Em razão da raça ou do sexo, ou da inteligência presumida, ou do status social, merecem prestá-lo ou não merecem, ou estão, de alguma forma, qualificadas para ele (WALZER, 2003, p. 225).

No caso brasileiro, esse conjunto de questões segue uma longa tradição e se relaciona com a questão social do país. A compreensão da atual realidade social exige que se faça "uma revisitação crítica da ação dos sujeitos e dos processos históricos que amalgamam cada sociedade." (WANDERLEY, 2004, p. 51). Assim, torna-se importante perceber que a questão social adquire um conteúdo especial na multidimensionalidade das relações sociais e na forma pela qual os sujeitos, individuais e coletivos, são determinados pelos processos e estruturas sociais, ao mesmo tempo em que instituem esses processos e estruturas. ${ }^{14}$ Importa, para os objetivos deste artigo, destacar que essas questões encontram-se imbricadas com as diversas fases e transformações apresentadas pelo mundo da produção e do trabalho.

Nessa perspectiva, Lopes (2008), ao refletir sobre os processos de exclusão e das mudanças verificadas na abordagem sobre a especificidade da questão social e da desigualdade no país, elucida as mudanças operadas no escopo da análise social.

Segundo o autor, a literatura acerca do tema

\footnotetext{
${ }^{14}$ Considerando os argumentos centrais deste artigo não se abordará com mais profundidade os aspectos relacionados a questão social brasileira. Uma boa análise sobre este debate pode ser encontrado em Bastos (1991); Rago (1997); Ianni (2002); Pizzio (2009), entre outros.
} 
permite afirmar que as condições que configuram a pobreza confirmam a dimensão de sujeito do pobre, na razão do controle de sua participação na economia. Porém, nos processos de exclusão produzidos no mundo neoliberal, mais que controlar ou negar o acesso ao trabalho ou ao consumo, controla e nega-se a própria condição de sujeiticidade (o que faz o ser humano ser sujeito) do indivíduo. Essa transformação qualificativa dos pressupostos antes identificados com os problemas decorrentes da desigualdade socioeconômica (a exploração, a marginalização, a pobreza), permite entrever que a injustiça primordial não é mais exclusivamente socioeconômica ou material, mas também de ordem simbólica (LOPES, 2008, p. 357).

Ora, essa constatação é de extrema relevância, uma vez que se observa que certas características e/ou situações, como ser desempregado ou estar subempregado, possuir carência, ser passível de, ou estar assistido, possuir baixa qualificação, viver na informalidade, dentre outros, são atributos e situações que se assemelham aos bens negativos de que fala Walzer (2003). Esses bens negativos, por assim dizer, quando combinados à situação de pobreza, compõem uma equação de difícil resposta, pois o imaginário que os fixa como marcas de inferioridade conduz à produção de uma hierarquia que diferencia os indivíduos em superiores e inferiores.

\section{Trabalho informal de rua: formas subordinadas de inserção}

É cada vez mais crescente o interesse da sociologia brasileira pelas questões que envolvem o mercado de trabalho e as formas e experiências associadas ao desemprego (Guimarães, 2009). O interesse justifica-se pelas transformações observadas no capitalismo a partir da década de 1970. As mudanças, em seu conjunto, são responsáveis por uma alteração conjuntural, cujos elementos-chave são a internacionalização do capital e o processo de globalização. Diante desse cenário, Francisco de Oliveira (2004, p. 3) destaca que

o capitalismo contemporâneo produz dois tipos antípodas de emprego. O primeiro, no topo da divisão social e técnica do trabalho, é o de altas performances técnico-científicas, nos ramos dedicados a pesquisar e programar o progresso técnico, isto é, as novas formas da acumulação. O segundo localiza-se no estrato mais baixo da mesma divisão social e técnica do trabalho: o trabalho mais banalizado, geralmente braçal, como paradoxo do progresso técnico-científico e devidamente instrumentalizado por este, uma espécie de forma virtual de extração da mais-valia. Os demais empregos, na indústria - sede da classe operária e nos serviços, estão em extinção: não apresentam nenhum crescimento há décadas e apenas renovam uma parte do antigo emprego. No espaço 
entre os dois extremos, uma miríade de ocupações que se encarregam da distribuição e circulação das formas da riqueza e do valor produzidos pelos extremos. Isso dá lugar a uma curiosa territorialidade dos novos empregos: nos países mais centrais do capitalismo globalizado, as ocupações banais são preenchidas por imigrantes - latinos nos Estados Unidos, indianos na Inglaterra, turcos e balcânicos na Alemanha, árabes e subsaarianos na França, nisseis brasileiros que viram decasséguis no Japão.

Tal diagnóstico abre uma excelente perspectiva analítica, pois vem ao encontro de questões anteriormente discutidas. De um lado, foi visto que o trabalho constituise em um bem e, nesse sentido, algumas atividades podem ser classificadas, como o trabalho árduo definido por Walzer (2003), e, consequentemente, identificadas como um bem negativo. De outro lado, a distribuição do trabalho no espaço público constitui-se em um elemento capaz de definir sujeitos e criar lugares sociais (microambientes).

Nesta direção, Oliveira (2004, p. 3) enfatiza, em relação às ocupações, que na atual conjuntura,

os novos empregos no topo da pirâmide são exclusividade do núcleo central desenvolvido e, em um ou outro caso, da periferia, o que contribui para concentrar ainda mais a renda: é o caso da Índia, o maior produtor mundial de software e de cinema. Na maior parte dos casos, servem apenas como exibição orgulhosa da capacidade científica potencial, mas raramente estão acoplados de maneira simbiótica ao sistema produtivo. $\mathrm{Na}$ periferia capitalista, avassalada pelo neoliberalismo globalizante, os números da última década são desalentadores: uma assustadora queima de empregos industriais e um crescimento exponencial da informalidade, que já nem tem força explicativa como conceito no Brasil, como alhures. Camelôs no Brasil e piqueteros na Argentina dizem menos da ocupação e mais da forma parapolítica de seus protestos e de sua ação contestadora. A tragédia dessa internacionalização da classe trabalhadora, ao contrário do que pregaram e pensaram Marx e Engels, é que mesmo um número substancial das novas ocupações de baixa qualificação é criado nos países centrais, que para lá atraem a força de trabalho da periferia. Então, a ocupação indireta gerada na periferia é de qualificação e remunerações ainda mais baixas do que as existentes no centro dinâmico. Por isso, ocorre a enorme informalidade.

No tocante à questão da informalidade, Noronha (2003) apresenta alguns elementos importantes ao debate proposto. Segundo o autor, no Brasil, o entendimento popular de trabalho formal ou informal define-se pela ordem jurídica e, neste caso, formal e informal está definido pela ausência ou não de carteira de trabalho assinada. $\mathrm{O}$ autor, entretanto, empreende um esforço 
conceitual, com o objetivo de redefinir a informalidade com base na forma pela qual os economistas, os juristas e a opinião pública ${ }^{15}$ o interpretam.

Na sua perspectiva, existem "três grandes matrizes de abordagem do tema: (1) os economistas com a oposição formal/informal; (2) os juristas, com a oposição legal/ilegal; e (3) o senso comum com a oposição justo/injusto." (NORONHA, 2003, p. 112). Para a vertente econômica, o informal refere-se a atividades periféricas não rentáveis e, especificamente no Brasil, significa não possuir carteira assinada, registro de autônomo ou status de empregador. A vertente jurídica interpreta a maior parte dessas situações como ilegais, uma vez que não existem contratos formais ou informais, mas legais e ilegais. Sob influência de ambos, a população tende a identificar o formal como a ausência de carteira assinada e, em decorrência, como injusto (NORONHA, 2003).

O autor amplia esse conjunto de questões com o intuito de dotar o conceito de trabalho informal de um conteúdo capaz de conferir maior precisão à mensuração e, consequentemente, ao entendimento do fenômeno no Brasil. Entretanto, de conformidade com os limites e objetivos do estudo proposto, esses aportes iniciais, em especial as noções de trabalho ideal/justo/aceitável e pessoalmente inaceitável/injusto/socialmente intolerável, são suficientes para o quadro de análise que se está delimitando. Segundo Noronha (2003), o quadro sobre o trabalho informal não se completa sem o entendimento do senso comum acerca dos contratos de trabalho. São conceitos construídos dialógica e difusamente, mediados por noções especializadas, divulgadas pela mídia, de juristas e economistas. Nesse sentido, é sempre importante destacar o papel que as ideias exercem no desenvolvimento e na configuração de realidades históricas.

$\mathrm{Na}$ perspectiva do autor, em se tratando de sociedades democráticas, a lei define o que é justo, muito embora muitos contratos considerados justos por determinados grupos não se encontrem previstos em lei. Conforme Noronha (2003, p. 121),

as linhas divisórias entre contratos de trabalho ideal, justo, aceitável pessoalmente inaceitável, injusto ou socialmente intolerável são tênues e misturam noções de necessidade pessoal, de eficiência, de éticas pessoais e familiares, de justiça e de valores, normas e hábitos socialmente definidos (muitos deles de natureza tradicional, não problematizados). Um trabalho pode ser aceitável, porém injusto, ou, inaceitável para um indivíduo, porém socialmente justo. $\mathrm{O}$ par justo e injusto diz respeito à esfera pública, enquanto as noções de ideal, aceitável e inaceitável se referem às preferências individuais, mas não as definem de forma linear ou mecânica.

\footnotetext{
${ }^{15}$ Por opinião pública, o autor designa "os grupos não especialistas, mas diretamente envolvidos ou interessados, tais como empregados, empregadores e seus representantes." (NORONHA, 2003, p. 112).
} 
Não se pode esquecer que, do mesmo modo, as concepções acerca do justo e do injusto, do aceitável e do inaceitável são moldadas por um amplo conjunto de valores morais e de éticas (Noronha, 2003). As preferências individuais encontram-se referenciadas em contextos institucionais de possibilidades dadas à satisfação pessoal, e,

embora a ideia de socialmente aceitável não seja correlata de justo, dada a resignação pragmática dos indivíduos à realidade do mercado de trabalho (expressa na frase: um emprego nunca é justo, mas assim é a vida), a ideia do socialmente inaceitável tende a ser próximo do injusto. Assim para o entendimento da forma como o homem comum enfrenta o conflito entre a abordagem jurídica (ilegal versus legal) e a econômica (informal versus formal) é mais apropriado investigarmos a noção de socialmente inaceitável do que qualquer outro termo acima mencionado. [...] Um trabalho pode ser inaceitável para uma pessoa devido a muitos fatores, tais como tarefas requeridas (por exemplo, atividades inferiores às qualificações não são bem vistas pelos empregados, essencialmente as degradantes), as condições do ambiente de trabalho (por exemplo, ambientes sujos e insalubres), ou relações pessoais (chefes autoritários), entre outras. Ademais, a percepção da ilegalidade de um tipo de contrato varia conforme as práticas populares locais. $O$ trabalho infantil, por exemplo, pode ser popularmente visto no Brasil como ilegal, apenas informal ou pode nem mesmo ser reconhecido como trabalho (e, portanto, como problema), dependendo de variáveis culturais e econômicas das regiões do país. $\mathrm{O}$ piso de direitos e benefícios para um contrato justo ou aceitável varia de acordo com o padrão contratual ai prevalecente, com as expectativas prévias de trabalho do indivíduo e de sua família, bem como em função das expectativas profissionais, o que por sua vez é definido por muitos outros elementos das histórias individuais, incluindo variáveis como grau de escolarização, sexo e idade (NORONHA, 2003, p. 121-123).

Nessa mesma linha de pensamento, Lopes (2008) examina as transformações sociais contemporâneas vivenciadas no mundo da produção e do trabalho e afirma que, em decorrência da crescente precarização da atividade remunerada e dos altos índices de desemprego, assiste-se a uma constante ampliação do mercado informal. Como efeito cascata,

isso tem provocado a proliferação de ocupações exercidas nos espaços antes reconhecidos como de circulação - ruas, praças e largos -, modificando a lógica do trabalho como atividade, que se confunde com o espaço ampliado da cidade. Nesse contexto, a distinção entre espaços de produção ou trabalho e espaços de circulação de pessoas e mercadorias é rompida, em prejuízo dos espaços públicos, gradualmente tomados por atividades ocupacionais e de geração de renda, modificando a percepção ambiental urbana e as identidades de 
vários segmentos sociais. Assim à ocupação de espaços públicos pelo trabalho informal antes restrito as atividades de trocas tradicionais que ocorriam em espaços reduzidos e localizados, foi se difundindo por diversos espaços públicos que concentram circulação de pessoas, impondo intervenções dos governos locais (LOPES, 2008, p. 358).

\section{Ainda na perspectiva desse autor, esses ordenamentos}

resultaram numa distribuição desigual dos espaços (considerando o potencial de venda de cada um, identificado pelos trabalhadores informais), hierarquizando os lugares e estratificando os trabalhadores informais segundo classes desiguais de inserção territorial. [...] essas referências, entre outras coletadas, mostram o aumento do desemprego, arrastando milhares de sujeitos para o mercado informal, produz uma ocupação espontânea dos espaços públicos da cidade pelo trabalho, gerando a necessidade de novas políticas públicas e modelos para o ordenamento urbano (na forma de ações formais e informais) que agem sobre a distribuição espacial do trabalho informal. Trata-se de uma forma de controle que opera pela produção de reformas urbanas que parcelam os espaços públicos em zonas hierarquizadas de comercio informal nos municípios. Esse ordenamentos implica tensões e conflitos sociais, como afirmou Wanderley (2004), uma vez que o controle do acesso dos trabalhadores informais no espaço público é visto pelos próprios trabalhadores como desrespeito. Assim, diversas manifestações desses trabalhadores, que vimos assistindo em regiões pesquisadas, mas também em capitais do país onde esse processo vem ocorrendo com regularidade, mostram que o parcelamento espacial imposto aos sujeitos em situação de vulnerabilidade não pressupõe a combinação entre o direito à diferença com participação econômica (LOPES, 2008, p. 359).

\section{Considerações finais}

Tendo como referência as questões até aqui debatidas, considera-se importante enfocar três aspectos. O primeiro aspecto diz respeito às atividades e ocupações concebidas como inaceitáveis ou injustas. Neste sentido, percebe-se uma inquietação em relação à dignidade do trabalho e, em igual medida, uma preocupação com a sua concretização, uma vez que ela é considerada como um direito fundamental, pois o trabalho digno ou dignificante está estabelecido na Constituição Federal de 1988 (BRASIL, 1990) ${ }^{16}$. O interesse pela questão também se encontra expresso nas agendas públicas de âmbito internacional ${ }^{17}$ e nacional. É

\footnotetext{
${ }^{16}$ Ver epígrafe no início deste trabalho.

${ }^{17}$ Para uma maior descrição dessas questões em âmbito internacional, ver OIT-Brasil (2006a).
} 
o caso, por exemplo, das ações que envolvem a Agenda Nacional do Trabalho Decente (OIT-BRASIL, 2006a).

Segundo as definições apresentadas no referido documento, o trabalho decente é uma condição fundamental para a superação da pobreza, a redução das desigualdades sociais, a garantia da governabilidade democrática e o desenvolvimento sustentável. Neste sentido, a OIT-Brasil (2006a), entende por trabalho decente aquele adequadamente remunerado, exercido em condições de liberdade, equidade e segurança e capaz de garantir uma vida digna. Trata-se da tentativa de enfrentamento de uma realidade em que se observa

a persistência de importantes desigualdades de rendimento entre homens e mulheres, assim como nos seus níveis e formas de inserção no trabalho, demonstra que ainda existem problemas de discriminação de gênero dentro e fora do mercado de trabalho. Homens e mulheres não estão integrados e não participam do mercado de trabalho em condições de igualdade de oportunidades, de disponibilidade de ativos e de poder de negociação. Além do gênero, a raça e a cor, a origem étnica, a origem social e a idade influem na qualidade e quantidade de oportunidades de emprego e renda a que homens e mulheres têm acesso, independentemente de suas aspirações, competências e conhecimentos (OIT-BRASIL, 2006b).

$\mathrm{O}$ segundo aspecto refere-se à sua caracterização e a seus aspectos organizacionais. O trabalho informal de rua ${ }^{18}$, nas suas formas organizativas, institui hierarquias ao subordinar sujeitos e distinguir lugares, nega o reconhecimento ao tipificar ocupações como socialmente degradantes e ao conferir-lhes um status negativo. No plano econômico, não promove e/ou limita a distribuição equânime de riquezas socialmente produzidas e de benefícios sociais, uma vez que esses últimos são concebidos e concedidos tendo como marco a carteira assinada. No caso dos trabalhadores autônomos, a situação não é muito diferente, pois os benefícios são concedidos em numero limitado. Em situações de paridade participativa não se garante uma apropriação econômica e de meios econômicos que possibilite a independência e a voz em debates públicos, ao mesmo tempo em que não se reconhecem as reivindicações como legítimas, desqualificando o sujeito no discurso público. Em tal contexto, o trabalho informal de rua constitui-se em um campo de conflito difuso. Por não apresentar limites claros em seu caráter difuso, expressa-se por meio da identificação de reivindicações, que na maioria das vezes, não se tornam demandas coletivas ou

\footnotetext{
${ }^{18}$ Utilizo a expressão trabalho informal de rua para enfatizar as diversas formas de trabalho que são desempenhadas no espaço público.
} 
politicamente organizadas. Trata-se de reivindicações fragmentadas, por vezes isoladas e pontuais.

Finalizando, o terceiro aspecto encontra-se imbricado com os anteriores e se refere ao trabalho como difusor de bens. Além do acesso aos bens de consumo, considerando-se o mercado informal, o trabalho em si mesmo, representa uma via de acesso a direitos sociais, que tem por objetivo compensar as assimetrias oriundas das relações de trabalho e poder, oferecer proteção contra os revezes econômicos e os infortúnios da vida. Neste sentido, Telles (2006, p. 177) destaca que

é certo que os modelos conhecidos de proteção social vem sendo postos em xeque pelas atuais mudanças no mundo do trabalho e que as conquistas sociais vem sendo demolidas pela onda neoliberal no mundo inteiro, também é verdade que esse questionamento e essa desmontagem reabrem as tensões, antinomias e contradições que estiveram na origem dessa história. E fazem ver as difíceis (e frágeis) relações entre o mundo social e o universo público da cidadania, na disjunção sempre reaberta entre a ordem legal que promete a igualdade e a reposição das desigualdades; entre exigência ética da justiça e os imperativos de eficácia da economia; entre universos culturais e valorativos de coletividades diversas e a lógica devastadora do mercado.

Entretanto, essa disjunção estrutura o terreno dos conflitos que inauguram a moderna questão social. Essas questões, se bem se avalia, apresentam um importante potencial analítico, uma vez que elas abrem espaço para refletir e reavivar o sentido político inscrito nos direitos.

Nessa direção, é importante destacar que o trabalho, como bem de acesso, constitui-se em um importante meio de inserção dos sujeitos nas cidades (espaço privilegiado de produção, circulação e usufruto de riquezas - bens materiais, culturais e simbólicos -, de concretude de experiências humanas e referência da vida moderna). Nesse contexto, o trabalho é uma importante fonte moral que contribui para a estima pessoal (autoestima), a qual pode constituir-se em um elemento essencial à redução, ou não, das assimetrias verificadas entre sujeitos ou grupos no espaço público. O trabalho, ao prover os sujeitos dos meios de garantir a sua subsistência ou suas necessidades básicas vitais, permite aos sujeitos perseguirem, em melhores condições e com maiores facilidades, outros bens como, por exemplo, os relativos aos direitos políticos e civis. Nesse caso, entendese que os direitos, em sua forma geral, podem ser definidos como bens.

Por fim, o trabalho produz um modelo originário de racionalidade, que opera discriminações sobre as relações que se estabelecem na vida coletiva. Com esta constatação, pode-se deduzir que o trabalho desenvolve racionalidades e raciocínios, com base em concepções diversas em termos culturais, religiosos, 
ético-morais e outros, as quais podem, ou não, estar em consonância umas com as outras, uma vez que advêm de interesses variados. Portanto, pode-se dizer - a exemplo das conclusões de Douglas e Isherwood (2009) sobre o papel dos bens nos processos interpretativos - que o trabalho oferece uma base racional para interpretação da realidade vivida e dos diversos arranjos presentes no modus vivendi. É importante ressaltar que essas observações finais não se esgotam em si mesmas, mas deixam em aberto caminhos para novos esforços intelectuais em torno do maior entendimento acerca das várias facetas da produção e reprodução da desigualdade social.

\section{Referências}

ALBORNOZ, S. O que é trabalho. 6. ed. São Paulo: Brasiliense, 2008.

ANTUNES, R. Os sentidos do trabalho: ensaio sobre a afirmação e a negação do trabalho. São Paulo: Boitempo, 1999.

BASTOS, E. R. A questão social e a sociologia paulista. São Paulo em Perspectiva, São Paulo, 5 (1), p. 31-39, 1991.

BÓGUS, L. M. M.; PASTERnAK, S. (Org.). Como anda São Paulo. Rio de Janeiro: Letra Capital; Observatório das Metrópoles, 2009.

BRASIL. Constituição da República Federativa do Brasil, promulgada em 5 de outubro de 1988. 4 ed. São Paulo: Saraiva, 1990.

COSTA, L. C. Marx e a barbárie capitalista. Material elaborado inicialmente para palestra realizada na Universidade Estadual de Maringá/PR, 1999. Disponível em: <http://www.uepg.br/nupes/marx.htm>. Acesso em 23 nov. 2010.

DOUGLAS, M. O mundo dos bens, vinte anos depois. Horizontes Antropológicos, Porto Alegre, ano 13, n. 28, p. 17-32, 2007.

DOUGLAS, M.; ISHERWOOD, B. O mundo dos Bens: para uma antropologia do consumo. 1. ed. Rio de Janeiro: Editora UFRJ, 2009.

FRIEDMANN, G. O objetivo da sociologia do trabalho. In: FRIEDMANN, G.; NAVILLE, P. Tratado de sociologia do trabalho. São Paulo: Cultrix, 1973. p. 19-44. 
GUIMARÃES, N. A. A sociologia dos mercados de trabalho, ontem e hoje. Novos Estudos Cebrap, São Paulo, n. 85, p. 151-170, 2009.

HOUIAISS. Dicionário eletrônico da língua portuguesa. Rio de Janeiro: Editora Objetiva, 2009.

IANNI, O. Tipos e mito do pensamento brasileiro. Revista Brasileira de Ciências Sociais, São Paulo, v. 17, n. 49, p. 5-10, jun./2002.

LOPES, J. R. Processos sociais de exclusão e políticas públicas de enfrentamento da pobreza. Cadernos CRH, Salvador, v. 21, n. 53, p. 349-363, 2008.

MAMÃO, G.; SANTOS, E. Onde está a inovação no Brasil? 2004. Disponível em: <http://www.institutoinovacao.com.br/downloads/artigo_200407_onde_ esta_inovacao.pdf $>$. Acesso em: 15 jul. 2010.

MARTINS, J. S. A exclusão e a nova desigualdade. São Paulo: Paulus, 1997.

MARX, K. O capital: crítica da economia política. Rio de Janeiro: Civilização Brasileira, 2002.

NORONHA, E. G. Informal, ilegal, injusto: percepções do mercado de trabalho no Brasil. Revista Brasileira de Ciências Sociais, v. 18, n. 53, p. 111-129, out./2003.

OLIVEIRA, F. Empregos globais, desemprego nacional: os empregos do ornitorrinco. Ibase. 2004. Disponível em: <http://www.ibase.br/modules.php? name $=$ Conteudo\&pid $=840>$. Acesso em: 04 ago. 2010.

OIT-BRASIL. Agenda nacional de trabalho decente. Brasília: Organização Internacional do Trabalho, 2006a.

- Trabalho decente nas Américas: agenda hemisférica 2006-2015. Brasília: OIT, 2006b.

PAOLI, M. C. P. M. Trabalhadores e cidadania: experiências do mundo público na história do Brasil moderno. Estudos Avançados, 3 (7), 1989.

PIZZIO, A. A qualificação social nos empreendimentos solidários de reciclagem. ESAC - Economia Solidária e Ação Cooperativa, São Leopoldo, n. 2 (1), p. 2334, 2007. 
- Desqualificação e qualificação social: uma análise teórico conceitual. Revista Mal-Estar e Subjetividade, Fortaleza, v. IX, n. 1, p. 209-232, 2009.

RAGO, M. Do cabaré ao lar: a utopia da cidade disciplinar. 3. ed. Rio de Janeiro: Paz e Terra, 1997.

RICCI, R. Um fordismo tupiniquim que concilia interesses. Revista do Instituto Humanitas Unisinos, São Leopoldo, ano X, n. 352, p. 8-10, 2010.

SANTOS, M. Espaço e método. 5. ed. São Paulo: USP, 2008.

SHORE, Cris. Comunidade. In: OUTTHWAITE, W.; BOTTOMORE, T. Dicionário do pensamento social do século XX. p. 115-117. Rio de Janeiro: Zahar, 1996.

TAYLOR, C. As fontes do self: a construção da identidade moderna. São Paulo: Loyola, 1997.

TELLES, V. S. Direitos sociais: afinal do que se trata? 2. ed. Belo Horizonte: UFMG, 2006.

WALZER, M. Esferas da Justiça. São Paulo: Martins Fontes, 2003.

WANDERLEY, L. E. W. A questão social no contexto da globalização: o caso latino-americano e caribenho. In: CASTEL, R.; WANDERLEY, L. E. W.; BELFIORE-WANDERLEY, M. Desigualdade e a questão social. 2. ed. São Paulo: Educ. 2004. p. 51-162.

Endereço para correspondência:

AlexPizzio-alexpizzio@uft.edu.br AV NS 15 - ALCNO 14 (109 Norte), Bloco III Sala 33, Pgdra 77001-090 Palmas/TO, Brasil 